\title{
Technique of robotic segmentectomy
}

\author{
Benjamin Wei, Robert Cerfolio
}

Division of Cardiothoracic Surgery, University of Alabama-Birmingham Medical Center, Birmingham, AL, USA

Correspondence to: Benjamin Wei, MD. Division of Cardiothoracic Surgery, University of Alabama at Birmingham, 703 19th St S, ZRB 739,

Birmingham, AL 352094, USA. Email: bwei@uab.edu.

\begin{abstract}
Robotic segmentectomy can be a useful technique for patients with suboptimal pulmonary reserve, or for small peripheral stage I tumors. Port placement and conduct of operation is described for the various segmentectomies. Results for robotic segmentectomy are comparable to that for video-assisted thoracoscopic surgery (VATS) segmentectomy.
\end{abstract}

Keywords: Robotic; segmentectomy; lung cancer; minimally invasive; lung resection

Received: 09 June 2017; Accepted: 08 August 2017; Published: 14 October 2017.

doi: 10.21037 /jovs.2017.08.13

View this article at: http://dx.doi.org/10.21037/jovs.2017.08.13

\section{Introduction}

Minimally invasive segmentectomy has traditionally been performed using video-assisted thoracoscopic surgery (VATS) techniques. The first robotic lobectomies were reported in 2003 by Morgan et al. and Ashton et al. $(1,2)$. The first robotic segmentectomies were reported in 2007 by Anderson et al. (3).

\section{Initial evaluation}

The evaluation of candidates for robotic segmentectomy includes the standard preoperative studies for patients undergoing pulmonary resection. For patients with suspected or biopsy-proven lung cancer, whole-body PET-CT scan is currently the standard of care. Pulmonary function testing including measurement of diffusion capacity (DLCO) and spirometry is routine. Mediastinal staging can consist of either endobronchial ultrasound guided fine-needle aspiration biopsy (EBUS-FNA) or mediastinoscopy, depending on expertise. Certain patients may warrant additional testing, including stress test, brain MRI if concern exists for metastatic disease, and/or dedicated computed tomography scan with intravenous contrast or MRI if concern exists for vascular or vertebral/nerve invasion, respectively.

Segmentectomy is generally reserved for small $(<2 \mathrm{~cm})$ tumors with clinical N0 disease that are located in a position where removal via a segment rather than a lobe will not compromise the surgical margin. Lobectomy remains the favored approach for minimizing the risk of locoregional recurrence even for stage I lung cancers (4). Segmentectomy, however, can be utilized in patients for whom lobectomy is a less palatable option due to concerns about pulmonary function. Removal of a segment of lung rather than a lobe permits patients with worse preoperative pulmonary function to have values for predicted postoperative forced expiratory volume in 1 second $\left(\mathrm{FEV}_{1}\right)$ and diffusion capacity (DLCO) greater than $40 \%$, which are considered safe thresholds in terms of perioperative risk $(5,6)$. Furthermore, evidence that segmentectomy may yield equivalent outcomes to lobectomy in stage I lung cancers is accumulating $(7,8)$.

\section{Conduct of operation}

\section{Preparation}

A well-trained team that communicates effectively is a priority for successful performance of robotic lobectomy. Criteria for a well-trained team include: documented scores of $70 \%$ or higher on simulator exercises, certificate of robotic safety training and cockpit awareness, weekly access to the robot, familiarity with the robotic and the instruments, and a mastery of the pulmonary artery from both an anterior and posterior approach. Currently, the Davinci surgical system console (Intuitive Surgical; Sunnyvale, CA, USA) is the only FDA-approved device 

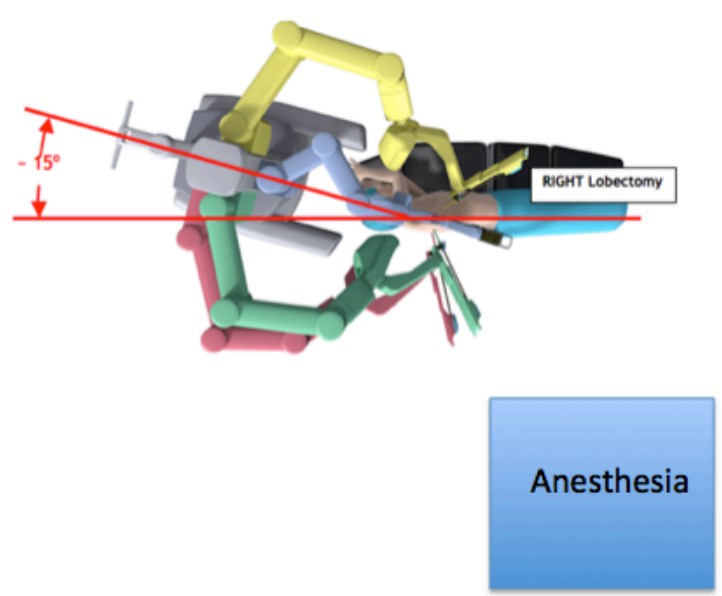

Figure 1 Location of robot, patient, and anesthesia for robotic segmentectomy.

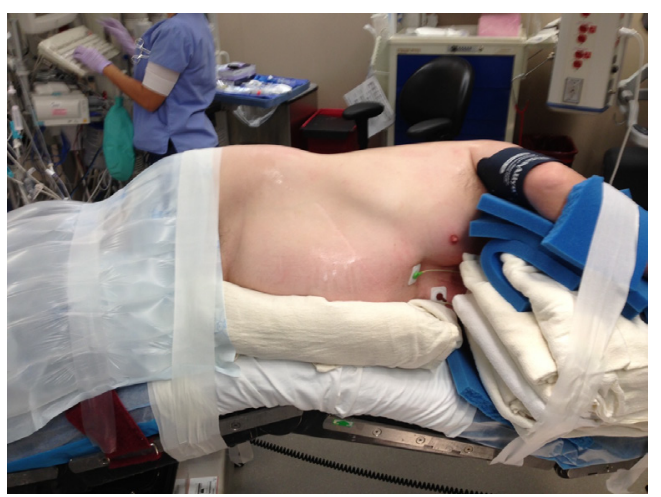

Figure 2 Positioning for robotic segmentectomy.

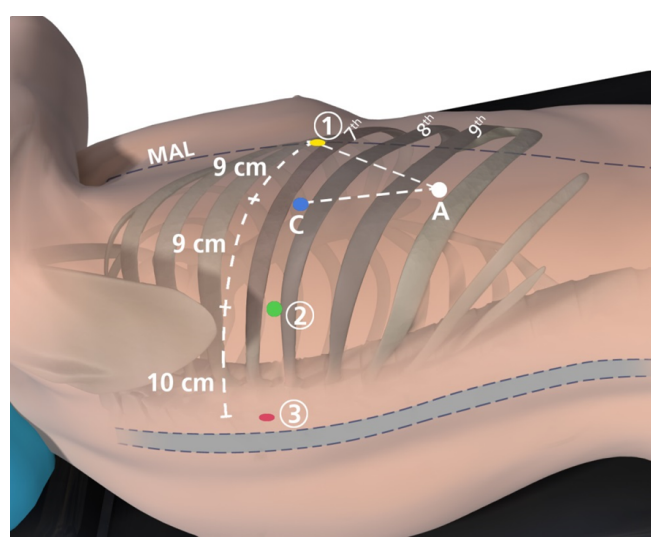

Figure 3 Port placement for robotic segmentectomy. The completely portal robotic segmentectomy with 4 robotic arms technique is shown. The circled numbers represent the robotic arms, $\mathrm{C}$ indicates the camera port, and $\mathrm{A}$ indicates the $15 \mathrm{~mm}$ access port. MAL, midaxillary line. available for robotic lobectomy. Proper location of the robot should be established prior to the operation. The third robotic arm will need to be located so that it will approach the patient from the posterior. For the Si system, the robot is driven from over to patient shoulder at a 15-degree angle off the longitudinal access of the patient. The patient will need to be turned so that the axis of the patient is 90 degrees away from the typical position (i.e., head near the anesthesia workstation) to facilitate this (Figure 1). The use of long ventilator tubing and wrapping up this and other monitoring lines with a towel secured to the side of the bed is helpful to minimize interference with the surgeon/ assistant. For the Xi system, the patient's head may remain near the anesthesia station, and the robot can approach the patient perpendicular to the direction of the bed. Precise placement of the double lumen endotracheal tube and the ability to tolerate single lung ventilation should be established prior to draping the patient, as repositioning the tube will be virtually impossible once the robot is docked.

\section{Patient positioning/port placement}

The patient is positioned in lateral decubitus position. Axillary rolls and arm boards are unnecessary (Figure 2). The robotic ports are typically inserted in the $8^{\text {th }}$ intercostal space. Typical port placement is shown in Figure 3 for a right robotic segmentectomy. The ports are marked as follows: robotic arm 3 (hereby referred to as the "accessory robotic arm") is located $2-3 \mathrm{~cm}$ lateral from the spinous process of the vertebral body, robotic arm 2 is $9-10 \mathrm{~cm}$ medial to robotic arm 3, the camera port is $9-10 \mathrm{~cm}$ medial to robotic arm 2, and robotic arm 1 is placed right above the diaphragm anteriorly. The assistant port is triangulated behind the camera port and the most anterior robotic port, and as inferior as possible without disrupting the diaphragm. We use a zero degree camera for this operation. Insufflation of the camera or assistant port with carbon dioxide is used to depress the diaphragm, decrease bleeding, and compress the lung.

\section{Mediastinal lymph node dissection}

After examining the pleura to confirm the absence of metastases, the next step during our performance of robotic segmentectomy is removal of the mediastinal lymph nodes, for staging and also to help expose the structures of the hilum.

* Right side: the inferior pulmonary ligament is divided. 
Lymph nodes at stations 8 and 9 are removed. The accessory robotic arm is used to retract the lower lobe medially and anteriorly in order to remove lymph nodes from station 7 . The accessory robotic arm is used to retract the upper lobe inferiorly during dissection of stations $2 \mathrm{R}$ and $4 \mathrm{R}$, clearing the space between the superior vena cava (SVC) anteriorly, the esophagus posteriorly, and the azygos vein inferiorly. Avoiding dissection too far superiorly can prevent injury to the right recurrent laryngeal nerve that wraps around the subclavian artery.

* Left side: the inferior pulmonary ligament is divided to facilitate the removal of lymph node station 9 . The nodes in station 8 are then removed. Station 7 is accessed in the space between the inferior pulmonary vein and lower lobe bronchus, lateral to the esophagus. The lower lobe is retracted medially/ anteriorly with the accessory robotic arm during this process. Absence of the lower lobe facilitates dissection of level 7 from the left. Finally, robotic arm three is used to wrap around the left upper lobe and pressed it inferior to allow dissection of stations 5 and 6 . Care should be taken while working in the aorto-pulmonary window to avoid injury to the left recurrent laryngeal nerve. Station $2 \mathrm{~L}$ cannot typically be accessed during left sided mediastinal lymph node dissection due to the presence of the aortic arch but the $4 \mathrm{~L}$ node is commonly removed.

* During performance of anatomic lung resections, removal of hilar, interlobar, and intersegmental lymph nodes helps facilitate dissection and permits individual pathologic analysis. If frozen section reveals the presence of malignancy in an intersegmental lymph node, the decision should generally be made to convert from segmentectomy to lobectomy assuming that the patient's lung function will tolerate it.

\section{Right upper lobe posterior segmentectomy}

The dissection of the hilum should be performed posteriorly after the lymph nodes in stations at levels 9, 8, and 7 have been removed. Then the level 11 lymph node between the right upper lobe and bronchus intermedius is removed. If this lymph node is positive for malignancy then a right upper lobectomy in the able patient. This identifies the posterior ascending artery, which can be absent in about $15-20 \%$ of patients. After identifying this artery from the back, which is possible in most patients, it can be divided. Then the posterior fissure between the right upper and lower lobes can be completed. With the lung retracted anteriorly by the accessory robotic arm, the bronchus is dissected more distally until the bifurcation is seen and the posterior segmental bronchus is encountered. This can then be isolated and divided. If the posterior ascending has not yet been taken (and it usually should be), it then is divided leaving only the vein. It is not necessary to take the posterior segmental vein but it can be seen in the fissure lying just superior to the pulmonary artery. The parenchyma is then stapled, separating the posterior segment from the remainder of the right upper lobe.

\section{Right upper lobe apical segmentectomy}

Posterior hilar dissection is performed as usual in order to obtain the level 9, 8, and then 7 and 11 lymph nodes. The lung is then retracted posteriorly by the accessory robotic arm. The visceral pleura overlying the upper lobe vein, truncus artery, and posterior ascending artery is divided. The upper lobe vein is dissected distally until the division of the apical vein becomes apparent. The apical vein is divided, exposing the truncus artery more fully. The branch of the truncus artery to the apex is then isolated and divided. With the lung still retracted posteriorly, the segmental bronchus to the apical segment is isolated and divided. All of these structures may be divided either via the assistant port or robotic arm $4(\mathrm{Xi})$ or $1(\mathrm{Si})$.

\section{Left upper apical trisegmentectomy (lingula-sparing lobectomy)}

Once the mediastinal lymph node dissection is complete, the area between the upper and lower lobes is dissected out posteriorly. This will reveal the posterior ascending artery, which can then be isolated and divided. This can be done from the assistant port, or with slightly more difficulty, from one of the robotic arms. The visceral pleura overlying the surface of the left main pulmonary artery as it comes out from under the aortic arch is divided, which should then reveal the anterior branches. The area between the anterior artery and the superior/posterior edge of the superior pulmonary vein is defined. The vein to the apical trisegment is then isolated anteriorly and divided. This can be done through the assistant port or from the robotic arm $3(\mathrm{Xi})$ or $1(\mathrm{Si})$. If the anterior artery is accessible at that point then it may be divided. However, usually the segmental bronchus to the upper division is stapled/divided 
first. This is identified by dissecting out the bronchus distally until the lingular bronchus is identified. As when performing a robotic left upper lobectomy, at times it may be easier to cut the segmental bronchus to access/divide the anterior branch of the artery, and then go back and staple it later. Once the airway has been divided, the left lung may be inflated, remembering to turn off insufflation first, in order to demarcate the segments. The parenchyma is then transected between the lingula and the apical trisegment.

\section{Lingulectomy}

The mediastinal lymph nodes, going from level 9, 8, 7 to $10 \mathrm{~L}$ ad then $4 \mathrm{~L}, 5$, and 6 . The fissure between the upper and lower lobes is first dissected out, in general from posterior to anterior. At times, if there is an incomplete fissure, the dissection may need to proceed from anterior, and a sub-adventitial plane developed so that the fissure above may be divided. The fissure can be divided with either ultrasonic energy or a stapler. The lingular arteries in the fissure are isolated and divided. This can be difficult due to the fact that the posterior ascending artery remain intact and therefore the pathway behind the lingular arteries that needs to be traversed is fairly narrow. This can be performed either via the assistant port, with proper retraction, or the left robotic arm. The superior pulmonary vein is dissected distally to expose the bifurcation of the upper division and lingular veins. The lingular vein may then be isolated and divided. This is done via the assistant port. Dividing the vein then exposes the left upper lobe bronchus, which again should be dissected out distally to identify the lingular bronchus, which is then isolated and divided (usually easiest from robotic arm 3). The parenchyma is then divided as described above for the left upper apical trisegmentectomy.

\section{Superior segmentectomy}

Either the vein or artery may be isolated first when performing a superior segmentectomy. For patients with a complete or nearly complete fissure, it is simple to dissect out, isolate and divide the superior segmental artery first. The lung may then be pulled anteriorly, and the posterior hilum dissected to extend the length on the bronchovascular structures. The superior segment vein should be visible, and can be isolated and divided next. This leave the superior segment bronchus. This may be approached either posteriorly or from the fissure. Reinflating the left lung can then help demarcate the superior segment from the basilar segments. The parenchyma may then be transected. The stapler may be deployed from the assistant port in most cases, though if a robotic stapler is available that can be used as well (in general from the left hand on a left sided superior segmentectomy and from the right hand on a right sided superior segmentectomy).

\section{Basilar segmentectomy}

In general it is simpler to use a vein-first technique when performing basilar segmentectomy. The ongoing vein to the basilar segments is isolated, taking care to preserve the superior segmental vein which should be visible as the most superior/posterior branch coming off of the inferior pulmonary vein. After division of the vein, the ongoing bronchus to the basilar segments should be visible. This is isolated, again taking care to avoid encompassing the superior segmental bronchus, which is going in a posterior/ medial direction when viewed from the lateral decubitus position. Once the bronchus is divided, the ongoing arteries to the basilar lobes can usually be isolated and divided as a single structure. The fissure should be dissected out posteriorly to confirm that the superior segmental artery is being preserved. Ventilating the lung then demarcates the basilar segments from the superior segment, and this is divided with the stapler. The stapler may be directed from the assistant port, or in some cases via robotic arm 3 (Xi) or $1(\mathrm{Si})$ on a left superior segmentectomy, and via the left robotic arm on a right superior segmentectomy (opposite that for a superior segmentectomy). If a single basilar segment is to be resected, dissection should proceed more distally in order to identify the relevant structures.

\section{Results}

Robotic segmentectomy can be done safely, with excellent perioperative outcomes and safety. Few conversions to thoracotomy may be anticipated. Our results are shown in Tables 1,2. Large series of robotic segmentectomy are summarized and compared to VATS segmentectomy in Table 3. Some surgeons have found that the operative time for robotic segmentectomy is longer than that for robotic lobectomy, and reported a slightly higher complication rate in terms of pleural space issues such as effusion and pneumothorax, but that has not been our experience (5). Although lower lobe sublobar resections appear to cause more of a decline in pulmonary function testing than upper lobe sublobar resections, these changes can recover by one 
Table 1 Patient characteristics, N=100 patients for planned segmentectomy

\begin{tabular}{|c|c|}
\hline Variable & $\begin{array}{l}\text { Patients who had a robotic } \\
\text { segmentectomy }\end{array}$ \\
\hline Age years, median & 71 \\
\hline \multicolumn{2}{|l|}{ Gender } \\
\hline Male & 50 \\
\hline Female & 50 \\
\hline \multicolumn{2}{|l|}{ Ethnicity (n) } \\
\hline White & 88 \\
\hline Black & 11 \\
\hline Other & 1 \\
\hline BMI, median (range) & $27.2(16.6-38.9)$ \\
\hline \multicolumn{2}{|l|}{ Type of segmentectomy } \\
\hline LUL & 46 (1 converted to lobectomy) \\
\hline Lingulectomy & 6 \\
\hline Anterior segment & 4 \\
\hline Apical segment & 7 \\
\hline Posterior segment & 28 \\
\hline LLL & 15 (1 converted to lobectomy) \\
\hline Superior segment & 14 \\
\hline RUL & 19 (1 converted to lobectomy) \\
\hline Posterior segment & 16 \\
\hline Apical & 2 \\
\hline RLL & 20 (4 converted to lobectomy) \\
\hline Superior segment & 13 \\
\hline Basilar segment & 2 \\
\hline Posterior segment & 1 \\
\hline \multicolumn{2}{|c|}{$\begin{array}{l}\text { Final pathology for-patients with lung } \\
\text { cancer }(\mathrm{N}=79)\end{array}$} \\
\hline T1aNOMO & 56 \\
\hline T1bNOM0 & 14 \\
\hline T2aNOMO & 9 \\
\hline \multicolumn{2}{|l|}{ Histology of primary lung cancer } \\
\hline Adenocarcinoma/lepidic pattern & 5 \\
\hline Adenocarcinoma & 34 \\
\hline $\begin{array}{l}\text { Adenocarcinoma + small cell } \\
\text { carcinoma }\end{array}$ & 1 \\
\hline Small cell carcinoma & 1 \\
\hline Squamous cell carcinoma & 29 \\
\hline Large cell neuroendocrine tumor & 9 \\
\hline Lung metastasis cell types & 10 \\
\hline Breast & 1 \\
\hline Melanoma & 1 \\
\hline
\end{tabular}

Table 1 (continued)
Table 1 (continued)

\begin{tabular}{|c|c|}
\hline Variable & $\begin{array}{c}\text { Patients who had a robotic } \\
\text { segmentectomy }\end{array}$ \\
\hline Prostate & 1 \\
\hline Pancreas & 2 \\
\hline Endometrioid & 1 \\
\hline Colon & 4 \\
\hline Smoking history & Yes (87\%) \\
\hline $\begin{array}{l}\text { Forced expiratory volume in } 1 \mathrm{~s} \text {, } \\
\text { median [range] (\%) }\end{array}$ & $74.5[28-150]$ \\
\hline $\begin{array}{l}\text { Diffusing capacity of lung for carbon } \\
\text { monoxide, median [range] (\%) }\end{array}$ & $67[25-138]$ \\
\hline \multicolumn{2}{|l|}{ Neoadjuvant therapy } \\
\hline Preoperative chemotherapy & 1 \\
\hline Preoperative radiation & 1 \\
\hline ENB tattooing & 16 \\
\hline \multicolumn{2}{|l|}{ Comorbidities (yes \%) } \\
\hline Hypertension & 65 \\
\hline Diabetes mellitus & 11 \\
\hline Congestive heart failure & 4.5 \\
\hline CAD, stent & 29 \\
\hline Pulmonary hypertension & 2 \\
\hline Hyperlipidemia & 41 \\
\hline COPD & 37 \\
\hline
\end{tabular}

BMI, body mass index; LUL, left upper lobe; LLL, left lower lobe; RUL, right upper lobe; RLL, right lower lobe; ENB, electromagnetic navigational bronchoscopy; CAD, coronary artery disease; COPD, chronic obstructive pulmonary disease.

Table 2 Patient outcomes

\begin{tabular}{lc} 
Variable & $\begin{array}{c}\text { Patients who had a robotic } \\
\text { segmentectomy ( }=100)\end{array}$ \\
\hline Intent to undergo robotic segmentectomy & 100 \\
Surgery started and ended robotically & 7 \\
Patients converted to lobectomy & 88 [46-205] \\
Operative time [minutes (range)] & 20 \\
Median measured blood loss (in cc.) & 5 \\
Minor post-op complications & 7 \\
Pneumothorax & 1 \\
Atrial fibrillation & $2 / 89$ (3\%) \\
Coagulopathy & 2 \\
Major post-op complications & 30 months \\
Pneumonia & \\
Length of hospital stay, median [range] days & \\
Median follow-up of patients with cancer & \\
Recurrence of cancer in ipsilateral lobe & \\
\hline
\end{tabular}


Table 3 Series of robotic and VATS segmentectomy

\begin{tabular}{|c|c|c|c|c|c|c|c|}
\hline Study & Type & No. of patients & Mean op time (min) & $\begin{array}{c}\text { Post-op } \\
\text { complications (\%) }\end{array}$ & LOS & $\begin{array}{l}\text { 60-day } \\
\text { mortality }\end{array}$ & $\begin{array}{l}\text { 90-day } \\
\text { mortality }\end{array}$ \\
\hline Cerfolio (9) & Robot & 100 & 88 & 2.0 & 2 & 0 & 0 \\
\hline Dylewski (10) & Robot & 35 & $180^{*}$ & 11.4 & $3^{*}$ & 0 & NA \\
\hline Pardolesi (11) & Robot & 17 & 189 & 17.6 & 5 & 0 & NA \\
\hline Toker (12) & Robot & 15 & $84 \pm 26^{\star *}$ & 19.0 & $4 \pm 1.4$ & NA & NA \\
\hline Yang (13) & Robot & 35 & 146 & 11.4 & 2 & 0 & NA \\
\hline Demir (14) & Robot & 34 & $76 \pm 23^{\star \star}$ & 24.3 & $4.65 \pm 1.94$ & NA & NA \\
\hline Demir (14) & VATS & 65 & $65 \pm 22$ & $0-1.5$ & $6.16 \pm 4.7$ & NA & NA \\
\hline Schuchert (15) & VATS & 104 & 136 & 26 & 5 & NA & NA \\
\hline Gossot (16) & VATS & 117 & $181 \pm 52$ & 11.7 & $5.5 \pm 2.2$ & NA & NA \\
\hline
\end{tabular}

*, included lobectomy and bilobectomy operations; ${ }^{*}$, reported as mean console time. VATS, video-assisted thoracoscopic surgery; op, operation; LOS,

length of stay; NA, not available.

year postoperatively (17).

\section{Acknowledgements}

None.

\section{Footnote}

Conflicts of Interest: The authors have no conflicts of interest to declare.

\section{References}

1. Morgan JA, Ginsburg ME, Sonett JR, et al. Advanced thoracoscopic procedures are facilitated by computer-aided robotic technology. Eur J Cardiothorac Surg 2003;23:8837; discussion 887.

2. Ashton RC Jr, Connery CP, Swistel DG, et al. Robotassisted lobectomy. J Thorac Cardiovasc Surg 2003;126:292-3.

3. Anderson CA, Hellan M, Falebella A, et al. Roboticassisted lung resection for malignant disease. Innovations 2007;2:254-8.

4. Martini N, Bains MS, Burt ME, et al. Incidence of local recurrence and second primary tumors in resected stage I lung cancer. J Thorac Cardiovasc Surg 1995;109:120-9.

5. Echavarria MF, Cheng AM, Velez-Cubian FO, et al. Comparison of pulmonary function tests and perioperative outcomes after robotic-assisted pulmonary lobectomy vs segmentectomy. Am J Surg 2016;212:1175-82.

6. Burt BM, Kosinski AS, Shrager JB, et al. Thoracoscopic lobectomy is associated with acceptable morbidity and mortality in patients with predicted postoperative forced expiratory volume in 1 second or diffusing capacity for carbon monoxide less than $40 \%$ of normal. J Thorac Cardiovasc Surg 2014;148:19-28, dicussion 28-29.e1.

7. Zhao ZR, Situ DR, Lau RWH. Comparison of segmentectomy and lobectomy in stage IA adenocarcinomas. J Thorac Oncol 2017;12:890-6.

8. Dziedzic R, Zurek W, Marjanski T, et al. Stage I nonsmall-cell lung cancer: long-term results of lobectomy versus sublobar resection from the Polish National Lung Cancer Registry. Eur J Cardiothorac Surg 2017 [Epub ahead of print].

9. Cerfolio RJ, Watson C, Minnich DJ, et al. One hundred planned robotic segmentectomies: early results, technical details, and preferred port placement. Ann Thorac Surg 2016;101:1089-95; Discussion 1095-6.

10. Dylewski, MR., Ohaeto AC, Pereira JF. Pulmonary resection using a total endoscopic robotic video-assisted approach. Semin Thorac Cardiovasc Surg, 2011;23:36-42.

11. Pardolesi A, Park B, Petrella F, et al. Robotic anatomic segmentectomy of the lung: technical aspects and initial results. Ann Thorac Surg 2012;94:929-34.

12. Toker A, Ayalp K, Uyumaz E, et al. Robotic lung segmentectomy for malignant and benign lesions. J Thorac Dis 2014;6:937-42.

13. Yang CF, D'Amico TA. Open, thoracoscopic and robotic segmentectomy for lung cancer. Ann Cardiothorac Surg 2014;3:142-52.

14. Demir A, Ayalp K, Ozkan B, et al. Robotic and videoassisted thoracic surgery lung segmentectomy for 
malignant and benign lesions. Interact Cardiovasc Thorac Surg 2015;20:304-9.

15. Schuchert MJ, Pettiford BL, Pennathur A, et al. Anatomic segmentectomy for stage I non-small-cell lung cancer: comparison of video-assisted thoracic surgery versus open approach. J Thorac Cardiovasc Surg 2009;138:1318-25.e1.

doi: $10.21037 /$ jovs.2017.08.13

Cite this article as: Wei B, Cerfolio R. Technique of robotic segmentectomy. J Vis Surg 2017;3:140.
16. Gossot D, Zaimi R, Fournel L, et al. Totally thoracoscopic pulmonary anatomic segmentectomies: technical considerations. J Thorac Dis 2013;5 Suppl 3:S200-6.

17. Kent MS, Mandrekar SJ, Landreneau R, et al. Impact of sublobar resection on pulmonary function: long-term results from American College of Surgeons Oncology Group Z4032 (Alliance). Ann Thorac Surg 2016;102:230-8. 